\title{
Understanding Black-African International Students' Experiences in United States Colleges and Universities Through Social Identity Theory
}

\author{
Diana Carole Awuor \\ Sam Houston State University, USA
}

\begin{abstract}
In this Research in Brief, Tajfel's (1970) social identity theory is explained and examined as potentially useful for analyzing the experiences of Black-African international students in U. S. colleges and universities. Race has been and still is a major issue in the United States. Through a review of literature, I sought to find out how Black-African international students' race affected their experiences in the United States.
\end{abstract}

Keywords: Black-African international students, race, social identity theory

\section{INTRODUCTION}

In May 2020, George Floyd, a Black man, was killed by police officers in Minneapolis, Minnesota. Floyd died by asphyxiation after one police officer placed his knee on Mr. Floyd's neck for a prolonged period of 8 minutes and 46 seconds (Romo, 2020). George Floyd's death came on the heels of numerous other deaths of Black men and women at the hands of police. Black-African International students (BAISs) are caught up in the middle of these racial struggles when they never had any experiences as members of racial minority groups in their countries. For better understanding, I refer to international students as those students who have left their home countries and crossed borders to different countries with their main purpose being studies/studying.

In this article, I will discuss the relationship between the racial experiences of BAISs in U.S. colleges and the ingroups with which they identify. I seek to 
identify if the experiences of BAISs in the United States are connected with their relationships with ingroups, outgroups, or intergroups. Tajfel's (1970) social identity theory (SIT) serves as the theoretical orientation guiding this inquiry. Through the lens of SIT, I analyze evidence from current published empirical work about how BAISs relate with ingroup and outgroup members. Ingroups include BAIS from sub-Saharan African countries like Kenya, Nigeria, Ghana, Mali, Uganda, Tanzania, South Africa, Zimbabwe, Rwanda, and Benin, whereas the members of outgroups can include international students who are not BAISs, American students, faculty, and staff.

\section{THEORETICAL FRAMEWORK}

SIT was proposed by Tajfel (1970), who performed studies using boys who were divided into ingroups, outgroups, and intergroups. One of the experiments required that the boys choose who to give money rewards within the intergroup. Many chose to give more of the money to those members who were part of their ingroups. There was no fairness. According to Tajfel (1970), discrimination and prejudice is most probable where there are ingroups forming an intergroup (intergroup is the parent group that holds several ingroups within it). Most people will favor those people who are within their ingroup and become prejudicial and discriminatory toward those who are in outgroups. This finding forms the foundation of SIT.

Zhou et al. (2008) considered SIT as a higher education model for international students' adaptation and culture shock. SIT explains how people who move to new places relate with their host cultures, putting into consideration their own self-esteem, favor of own group members (ingroup), and the degrading that they undergo as nongroup members of the outgroups. Belonging to a social group comes with both pros and cons. A group member in an intergroup may be denied a service by members of different groups from theirs. A member of an ingroup also stands a chance of being a beneficiary of services offered only to members of their ingroup.

According to Zhou et al. (2008), SIT enables prediction of behaviors of individuals depending on how they relate with groups. BAISs, for instance, may perceive that people who do not belong to any of the BAIS racial or ethnic ingroups will be racially prejudicial toward BAISs as this is what international media propagates about the United States globally. This psychological grouping makes it possible to predict BAISs' interaction with African Americans, Caucasians, and members of other races. Disappointment may arise when the treatment BAISs receive from African Americans is the opposite of their expectations because of the perception that they belonged to the same ingroup as Africa Americans: the Black race ingroup. The expectation of favoritism within their ingroups could cause BAISs to perceive predominantly White institutions (PWIs) as institutions where they would receive poor treatment because they did not belong to the White majority ingroup, and historically Black colleges and universities (HBCUs) as institutions where BAISs expect better treatment because they blend in with the majority who are Black. 


\section{LITERATURE REVIEW}

\section{Number of BAISs in the United States}

For the past 2 academic years, the number of BAISs in the United States has been on the increase according to the Institute of International Education (2019). In the 2018-2019 academic year, the number of BAISs from sub-Saharan Africa enrolled in U.S. colleges was 40,290, with Nigeria, Ghana, and Kenya ranking first, second, and third, respectively (see Table 1). The sub-Saharan region is mostly inhabited by Black-Africans.

Table 1: Enrollment Trends for Sub-Saharan Africa International Students (Top Five Exporters)

\begin{tabular}{lccc}
\hline $\begin{array}{l}\text { Countries of } \\
\text { origin }\end{array}$ & $\begin{array}{c}2017-2018 \\
\text { academic year }\end{array}$ & $\begin{array}{c}2018-2019 \\
\text { academic year }\end{array}$ & \% change \\
\hline Nigeria & 12,693 & 13,423 & 5.8 \\
Kenya & 3,322 & 3,451 & 3.9 \\
Ghana & 3,213 & 3,661 & 13.9 \\
South Africa & 2,040 & 2,042 & 0.1 \\
Ethiopia & 2,118 & 2,061 & -2.7 \\
\hline
\end{tabular}

Note. Nigeria's numbers are higher than all the other four countries combined. Adopted from the Institute for International Education Open Doors (2019) fact sheet.

\section{BAISs' Racial Experiences in U.S. Colleges}

BAISs work harder to prove they are intelligent because they are stereotyped as lacking in intelligence and intellectually inferior (Constantine et. al., 2005). Intelligence is often associated with White ingroups, and the Black ingroup members are often considered lacking in intelligence. BAISs at PWIs are not considered intelligent until they prove themselves and have reported being awarded grades they did not deserve and having academic advisors who were reluctant to offer them guidance (Inyama et al., 2016). In her study of 15 graduate students from sub-Saharan Africa, Beoku-Betts (2004) noted that BAISs perceived that their assigned mentors began to take their mentoring of BAISs seriously only when they found out that BAISs were as intelligent as their other students. Additionally, Beoku-Betts discovered BAISs' non-Black peers had the perception that BAISs could not complete their education. These perceptions from mentors and fellow students made BAISs feel isolated in a foreign country.

Constantine et al. (2005) investigated the cultural adjustment experiences of BAISs and indicated that White professors and White teaching assistants used racial slurs like "stupid nigger" to refer to BAISs (Constantine et al., 2005, p. 61). This indicates the conflict between two different racial groups within an intergroup; BAISs being in their ingroup and Whites in BAISs' outgroup. The researchers also reported that BAISs experienced racially prejudicial treatment 
from African Americans and fellow non-BAISs. Some of their respondents reported that African Americans would not date them because they thought that BAISs were "too Black" (Constantine et al., 2005, p. 61). Most BAISs perceive that African Americans belong to their ingroup (Black people's ingroup) only to find out that the Black race is an entire intergroup with several ethnic and cultural groups within it. In the Black race intergroup, BAISs belong to a different ingroup and African Americans belong to BAISs' outgroup. Additionally, other nonBAISs reported not wanting to relate to BAISs because they were "afraid" of BAISs due to the stereotypes they were exposed to about Africans in their countries (Constantine et al., 2005, p. 61). The situation with the non-BAISs presents the international students' population as an intergroup on its own.

Mitchell et al. (2017) conducted a qualitative study to explore how international students in the United States learned about and were impacted by race and racism. The researchers found that most international students learned about race and racism through the media like international media houses (e.g., George Floyd's killing was broadcasted globally and protests related to his killing were also organized globally) and education (e.g., African American studies, United States history, which includes civil rights movements, etc.). However, BAISs learned about racism through experience too. Mitchell et al. (2017) reported that some BAISs were victims of racial microaggressions by their professors and peers in U.S. higher education institutions. Racial microaggressions are offenses that are racially related, which Black people perceive as being directed to them through communication (Sue et al., 2007).

\section{CONCLUSION}

Society is a conglomeration. This means that higher education institutions are also conglomerations because they are formed by different groups coming together. These different groups are based on race, skin color, ethnicity, socioeconomic status, religion, gender, sexual orientations, etc. BAISs are part of the Black race, dark skinned, and African groups. Higher education practitioners should understand group dynamics through the lens of SIT in order to comprehend the experiences of BAISs and help improve BAISs' adjustment experience in the midst of a society riddled with racism.

\section{Recommendations}

More research focusing on the racial experiences of BAISs, especially with regard to their relationships with outgroups, is needed to aid future prospective BAISs in making informed decisions regarding studying in the United States. Findings from such studies can also create awareness among members of BAIS outgroups, especially those who are American citizens, to help them create a more conducive environment for BAISs' adjustment. 


\section{REFERENCES}

Beoku-Betts, J. A. (2004). African women pursuing graduate studies in the sciences. Racism, gender bias, and third world marginality. National Women's Studies Association Journal, 16(1), 116-135.

Constantine, M. G., Anderson, G. M., Berkel, L. A., Caldwell, L. D., \& Utsey, S. O. (2005). Examining the cultural adjustment experiences of African international college students: A qualitative analysis. Journal of Counseling Psychology, 52(1), 57-66.

Institute of International Education. (2019). Open Doors 2019 fast facts. Retrieved April 22, 2021, from https://opendoorsdata.org/wpcontent/uploads/2020/11/Open-Doors-Fast-Facts-2010-2019.pdf

Inyama, D., Williams, A., \& McCauley, K. (2016). Experiences of African students in predominantly White institutions: A literature overview. Nursing Research and Practice, 2016, Article 5703015. http://doi.org/10.1155/2016/5703015

Mitchell, D., Jr., Steele, T., Marie, J., \& Timm, K. (2017). Learning race and racism while learning: Experiences of international students pursuing higher education in the midwestern United States. American Educational Research Association Open, 3(3), 1-15. https://doi.org/10.1177/2332858417720402

Romo, V. (2020, June 1). County officials rule George Flyod death was a homicide. NPR. https://www.npr.org/2020/06/01/867219130/george-floydindependent-autopsy-homicide-by-asphyxia

Sue, D. W., Capodilupo, C. M., Torino, G. C., Bucceri, J. M., Holder, A. M. B., Nadal, K. L., \& Esquilin, M. (2007). Racial microaggressions in everyday life: Implications for clinical practice. American Psychologist, 62, 271-286. http://dx.doi.org/10.1037/0003-066X.62.4.271

Tajfel, H. (1970). Experiments in intergroup discrimination. Scientific American, 223, 96-102.

Zhou, Y., Jinda-Snape, D., Topping, K., \& Todman, J. (2008). Theoretical models of culture shock and adaptation in international students in higher education. Studies in Higher Education, 33(1), 63-75. https://doi.org/10.1080/03075070701794833

DIANA AWUOR, MA, is a doctoral candidate in the Department of Educational Leadership at Sam Houston State University. Her major research interests lie in the areas of international education, Black-African international students, diversity, multilingualism in education and multiculturalism.

Email: awuordiana2020@gmail.com 